\title{
Nucleophosmin Gene Mutation in Acute Myeloblastic Leukemia: Apoptotic Role
}

\author{
Khaled SAA ${ }^{1,2,3 *}$, Burthem J², Elnoor EBEA ${ }^{2}$, ElToni LF ${ }^{1}$, Ahmed HN $^{2}$ and Ahmed SN 4 \\ ${ }^{1}$ Department of Internal Medicine, Egypt \\ ${ }^{2}$ Clinical Hematology Unit, Assiut University Hospital, Assiut, Egypt \\ ${ }^{3}$ Unit of Bone Marrow Transplantation, South Egypt Cancer Institute, Assiut University, Egypt \\ ${ }^{4}$ Centre for Haematological Oncology, Manchester University, UK
}

\begin{abstract}
Introduction and objectives: Since Falini and his co-workers reported the expression of nucleophosmin (NPM) gene mutation in acute myeloblastic leukemia (AML), and various research in succession clarified the role of mNPM in AML. We previously studied the proliferative role of $\mathrm{MNPM}$ in AML in a trial to discover its role in AML development and leukemogenesis. This study aimed to complete the scenario and investigate the apoptotic role of mNPM AML. Another objective was to assess the effect of NPM mutational state on response to etoposide treatment in AML.

Materials and methods: In this study human leukemia cell lines, HL60 and OCI-AML3 were used as models for AMLs bearing wild type (wt) and mutated (m) NPM, respectively. The study was conducted by using viability studies. The obtained results were reaffirmed by immunocytochemical and immunoblotting analyses. Results were interpreted and presented with the appropriate computer softwares.

Results and conclusions: Interpretation of data showed normal growth and delayed apoptotic response of etoposide treated cells bearing mNPM as compared with cells carrying wtNPM and the control. Also we noted irreversible cytoplasmic translocation of NPM that was dependent on the duration and extent of the etoposide induced cytotoxicity in cells with wtNPM. Proteomic analysis of NPM revealed that protein expression in the etoposid lysates was approximately similar to the untreated controls We concluded that wtNPM has a pro-apoptotic effect while mNPM has an anti-apoptotic effect, suggested that therapeutic response to etoposide treatment in AML could be variable from one patient to another depending on the molecular basis of leukemia development in each case. Also, it was concluded that AML cells bearing nucleophosmin mutation are resistant to etoposide effect.
\end{abstract}

Keywords: AML; Etoposide; Apoptosis; Nucleophosmin

\section{Introduction}

Acute myeloid leukemia (AML) is an aggressive form of hematopoietic disorders, which possesses a variable therapeutic response to conventional chemotherapy, from one patient to another [1]. Lots of prognostic factors had been identified in AML and were grouped into two major groups, patient and disease centered factors $[2,3]$. However, the cytogenetic and molecular profile of the disease is considered the most important determinant of response to treatment in AML [4].

Nucleophosmin gene mutation (mNPM) was reported in $60 \%$ of de novo AML with normal cytogenetics [5]. AML with mNPM (NPMc+ AML) is associated with a peculiar clinical, hematologic, immunophenotypic and even cytogenetic features [6]. Also, NPMc+ AML displays a good response to induction chemotherapy [7]. Accordingly, mNPM could be considered the most important molecular marker in AML [8].

NPM was observed to act as a regulator of P53 activation, through interference with P53 transcription. Also, NPM was found to act as a cellular thermostat that adjust P53 activation in response to DNA damage. Thus, in case of mild DNA damage, NPM binds P53 N-terminal domain and hinders its phosphorylation. On the contrary, at higher levels of DNA damage, NPM itself is down regulated; freeing P53 from its control and subsequently P53 activation occurs. Since NPM seems to be very important in keeping normal cellular homeostasis in normal cells. And as NPM is overexpressed in malignant cells, this could suggest marked repression of P53 functions with subsequent overproliferation and oncogenesis [9].
Etoposide is a topoisomerase II inhibitor that has a wide spectrum of antineoplastic effects against a variety of hematological and non hematological neoplasms [10]. Etoposide could be administered as an outpatient therapy, also it is well tolerated [11]. In AML, etoposide is a second line chemotherapy and is recommended as a combination regimen for refractory or relapsed AMLs [11,12]. Although most of the chemotherapeutic regimens of AML have been revised based on the recent cytogenetic and molecular classification of AML [13]. However, adjunctive etoposide therapy in AML is still clinically based [12].

We previously reported that the cytoplasmically located mNPM expressed by OCI-AML3 cell line cells is phosphorylated at Thr199. As NPM phosphorylation was found to be the key factor for its activation and functions. Accordingly we implicated mNPM in AML leukemogenesis so we studied its role in proliferation of AML cell line cells [14-16]. This study aimed to complete the scenario of mNPM in AML pathogenesis by investigating its apoptotic role. Another objective was to study the effect of mNPM on response to etoposide

*Corresponding author: Khaled SAA, Department of Internal Medicine, Hematology and BMT Unit, Assiut University Hospital, Assiut, Egypt, Tel: +201064170058; E-mail: safaakhaled2003@gmail.com

Received November 10, 2019; Accepted November 18, 2019; Published November 22, 2019

Citation: Khaled SAA, Burthem J, Elnoor EBEA, EIToni LF, Ahmed HN, et al. (2019) Nucleophosmin Gene Mutation in Acute Myeloblastic Leukemia: Apoptotic Role. J Blood Lymph 9: 254.

Copyright: (c) 2019 Khaled SAA, et al. This is an open-access article distributed under the terms of the Creative Commons Attribution License, which permits unrestricted use, distribution, and reproduction in any medium, provided the original author and source are credited. 
treatment of AML. To do so we meticulously explore mNPM during etoposide induced apoptosis of AML cell line cells.

The study was conducted on both NPM moieties (wtNPm \& mNPM) using type A mNPM as an example for mNPM. Nevertheless, some technical and ethical reasons limited this study to be in vitro study only. Accordingly, human leukemia cell lines HL60 and OCIAML3 were used as models for (AML carrying wild type NPM) NPMcand NPMc+ (AML with mutated NPM) AMLs, respectively.

\section{Materials and Methods}

\section{Biological materials}

Human leukaemia cell lines: Two different human leukaemia cell lines were used, OCI-AML3 Cells were purchased from DSMZ (Deutche Sammlung von Mikroorganismen und Zellkulturen $\mathrm{GmbH}$, German collection of micro-organisms and culture) (ACC, 582). Mutational analysis of NPM in these cells revealed TCTG duplication at 956-959 of exon 12- of NPM gene (GenBank accession number NPM-002520). This was correspondent to type A NPM mutation that was found in NPMc+AML [17]. Accordingly, OCI-AML3 was used as a cell line model for NPMc+AML.

HL60 cells were purchased from DSMZ (ACC, 3); we used HL60 as a cell line model for NPMc- AML (NPM-cytoplasmic negative).

Antibodies: Most of the methods used in this research were based on the antigen-antibody interaction and principle. Two types of antibodies were used, primary and secondary antibodies. Table 1, illustrated the specificity, reactivity, supplier and applications of the primary antibodies that were used throughout this research work.

A panel of species specific flourophore conjugated secondary antibodies was used. These antibodies are Texas red (TR) conjugated (abcam 6003), and Fluorescence Isothiocyanate (FITC) conjugated (abcam 6717). An enzyme linked secondary antibody was used in proteomic analysis that was obtained from GE-Healthcare.

Other materials: Other materials like chemicals, equipments, instruments and computer softwares will be mentioned together with the methods.

\section{Methods}

Cell culture and viability studies: Cells were grown in RPMI media 1640 , with GlutaMAX ${ }^{\mathrm{TM}}$ supplemented with $10 \%$ FCS and $1 \%$ Pen/ strep (GIBCO, 61870-044, 10108-165, and 15070-063), at optimum gas and temperature conditions $\left(37^{\circ} \mathrm{C}, 5 \% \mathrm{CO}_{2}\right)$. Cells were freshly fed, then each culture was divided into two, $24 \mathrm{~h}$ later etoposide (VP16, Callbiochem, cat. No. 341205) was added to one media for induction of apoptosis. While the other left to grow normally (control). Etoposide was dissolved in dimethyl sulfoxide, then diluted with normal saline making a solution of $0.25 \mathrm{~g} / \mathrm{L}, 10 \mu \mathrm{M}$ was added to the test culture. The etoposide treated cells were referred to as etoHL60 and etoOCI-

\begin{tabular}{|l|c|c|c|}
\hline \multicolumn{1}{|c|}{ Specificity\& reactivity } & Clone & Supplier & Applications \\
\hline NPM C-terminus & FC-61991 & Zymed & ICC,WB, IP \\
\hline Phospho-NPMThr199 & 3541 & Cell Signalling & ICC,WB, IP \\
\hline NPM a. a. 23-38\&226-240 & Ab15440 & Abcam & ICC,WB, IP \\
\hline NPM N-terminal\&14a.aALK & NA24 & Thermo & Proteomics \\
\hline
\end{tabular}

Table 1: Specificity, reactivity, clone, supplier and applications of the primary antibodies that have been used throughout the research.

N.B. ICC: Immunocytochemistry; WB: Western Blotting; IP: Immunopericipitation aa: Amino Acid Sequence; phospho-NPM Thr199: NPM Phosphorylated At Threonine 199.
AML3. Cells were extracted, from the apoptotic and normal cultures, first at 0 -time and then every $4 \mathrm{~h}$ for $24 \mathrm{~h}$, to estimate their apoptosis and death rates by the trypan blue exclusion test.

Immunoblot analysis: Cells were pelleted, washed, and lysed by incubation with RIPA buffer containing $50 \mathrm{mM}$ Tris- $\mathrm{HCl}$ ( $\mathrm{pH} 7.4$ ), $150 \mathrm{mM} \mathrm{NaCl}, 1 \%$ triton-x, $10 \%$ sodium deoxycholate, $1 \mathrm{mM}$ EDTA). Lysates were centrifuged and the supernatant was collected, diluted then loaded into $12 \%$ SDS-PAGE gels and electroblotted with the same protocol described by others in 1979 [18], with some modifications. The obtained protein bands were blotted with a panel of anti-human NPM antibodies, namely, ab15440, FC61991, NA24 and phosphorNPM Thr199. Both the eto-treated and untreated lysates were separated with the same gel and blotted in a single membrane, thus technical differences will not play a role in the obtained results. Lastly, images of the obtained blot were captured using a Kodak X-Ray film and cassette (Sigma Aldrich, Kodak Biomax XAR Film size 18/24 cm). Films were developed using Kodak developer/fixer kit. The obtained protein bands were then marked compared to the BIO-RAD Precision Protein Standards.

Immunocytochemistry (Immunostaining): Cytospins were prepared from both apoptotic and normal cultures, then mounted in DAPI. Then, we followed the manufacturer recommended protocols for immunostaining of cytospins for wtNPM, NPM ab15440 and phospho-NPM Thr199. Next, the Slides were viewed, with the Nikon Eclipse 80I fluorescence microscope (ICCT technologies, Canada), equipped with 3 fluorescence filter cubes. The obtained Images were grabbed with the Hamamatsu ORCA HR (C4742-95-12HR) high resolution digital camera, with full remote control from PC. Another fast high sensitivity black and white camera was used for low intensity fluorescence slides. Analysis of the obtained images with the NISelements software was carried out.

\section{Results}

\section{Normal growth of etoposide treated cells bearing mNPM as compared with cells carrying WtNPM and the control}

The viability study results were mathematically estimated with the MATLAB 7.1 software program. The obtained results revealed arrested growth of etoHL60 compared with the control. After $4 \mathrm{~h}$ incubation with etoposide, HL60 viability decreased from $100 \%$ to $95.8 \%$ with respect to the control. Further decline in HL60 viability was noted over the $24 \mathrm{~h}$ incubation period with etoposide. This decline was progressive until the viability reached $66 \%$ after 24 -h, as summarized in table 2 . The growth curve of etoHL60 revealed a gradual progressive decline in the total number of viable cells over the time intervals indicated in Figure 1A. On the contrary, the growth curve of the control showed a progressive increment in the number of viable cells over time, reaching its peak around $12 \mathrm{~h}$ (doubling time). After that, the cellular viability starts to decline giving the curve an inverted- $\mathrm{V}$ shape.

On the other hand, etoOCI-AML3 cells were still viable up to $100 \%$ after $4 \mathrm{~h}$ incubation with etoposide. The growth curve of the etoOCIAML3 was nearly similar to the curve of the untreated control. The curve showed gradual progressive increase in the number of viable cells over the time intervals indicated in Figure 1B. This increment reached its peak around $16 \mathrm{~h}$. Next, the viability started to decline until it reached its lowest levels by $24 \mathrm{~h}$. However, this decline was more obvious with etoOCI-AML3 as compared with the untreated control, where eto-OCI-AML3 viability dropped from $100 \%$ at 4 h to $87.2 \%$ after $24 \mathrm{~h}$, while that of the control from $100 \%$ to $97.4 \%$ only. 
Citation: Khaled SAA, Burthem J, Elnoor EBEA, EIToni LF, Ahmed HN, et al. (2019) Nucleophosmin Gene Mutation in Acute Myeloblastic Leukemia: Apoptotic Role. J Blood Lymph 9: 254.

Page 3 of 7

\begin{tabular}{|c|c|c|c|c|c|c|c|c|}
\hline \multirow[t]{2}{*}{ Time(h) } & \multicolumn{2}{|c|}{ EtoHL60 } & \multicolumn{2}{|c|}{ HL60 Control } & \multicolumn{2}{|c|}{ EtoOCI-AML3 } & \multicolumn{2}{|c|}{$\begin{array}{c}\text { OCI-AML3 } \\
\text { Control }\end{array}$} \\
\hline & \%living & \%dead & \%living & $\%$ dead & \%living & $\%$ dead & \%living & \%dead \\
\hline 0 & 100 & 0 & 100 & 0 & 100 & 0 & 100 & 0 \\
\hline 4 & 95.8 & 4.2 & 100 & 0 & 100 & 0 & 100 & 0 \\
\hline 8 & 89.0 & 11.0 & 100 & 0 & 99.5 & 0.5 & 99.7 & 0.3 \\
\hline 12 & 83.8 & 16.2 & 99.6 & 0.4 & 99 & 1 & 99.5 & 0.5 \\
\hline 16 & 77.7 & 22.3 & 99.3 & 0.7 & 98 & 2 & 99.0 & 1.0 \\
\hline 20 & 71.0 & 29.0 & 99.0 & 1.0 & 94 & 6 & 98.6 & 1.4 \\
\hline 24 & 66.0 & 34.0 & 98.5 & 1.5 & 87.2 & 12.8 & 97.4 & 2.6 \\
\hline
\end{tabular}

Table 2: Results of the viability study of the etoHL60 and etoOCI-AML3 and their equivalent untreated controls over 24-h incubation period. The study was conducted with the trypan blue exclusion test, and the results were calculated with the MATLAB 7.1 software program.

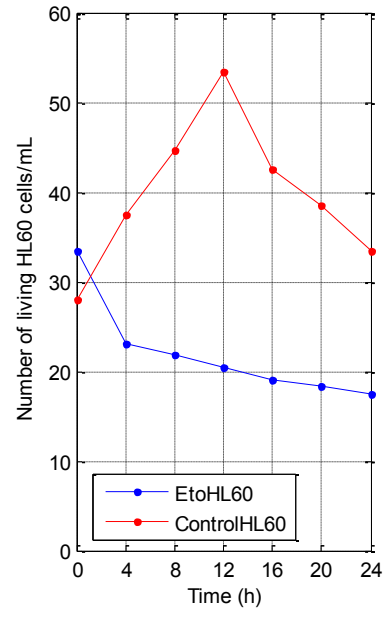

(A)

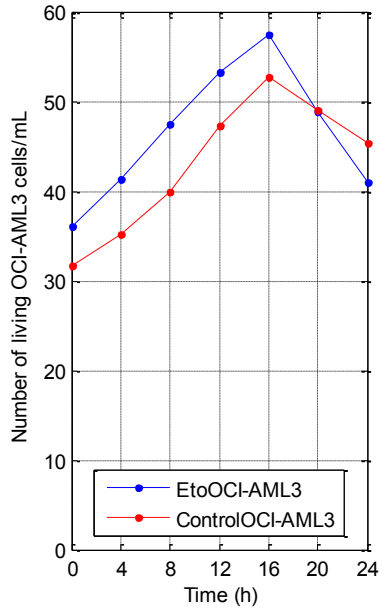

(B)

Figure 1: Growth curves of (A) etoHL60 and control HL60 and (B) etoOCl$\mathrm{AML} 3$ and control $\mathrm{OCl}-\mathrm{AML} 3$, over the time intervals indicated in the figure.

The above mentioned findings were confirmed by examining cytospins, obtained from the apoptotic and normal cultures. Analysis of the obtained images showed cessation of HL60 growth after $4 \mathrm{~h}$ treatment with etoposide as compared with their control. This was determined by the absence of actively dividing cells (mitotic figures) in most of the available microscopic fields, as depicted in Figure 2A and $2 \mathrm{~B}$.

In sharp contrast to etoHL60, etoOCI-AML3 cells were still healthy and actively dividing after 4 -h incubation with etoposide. Furthermore, microscopic examination of etoOCI-AML3 cytospins revealed cellular morphology and mitotic figures nearly similar to that of the OCIAML3 control, Figure 2C and 2D.

Images of cytospins obtained after $24 \mathrm{~h}$ incubation with etoposide, showed arrested growth of both HL60 and OCI-AML 3 cells as compared to their relevant untreated controls. In these cytospins, mitotic figures were detected only in the control slides, as shown in Figure 3.

Delayed apoptotic response of etoposide treated cells bearing mNPM as compared with cells carrying WtNPM and the control

Incubating HL60 cells for $24 \mathrm{~h}$ in the presence of etoposide produced a rapid accelerated cellular death where the viability study results showed cell death of $4.2 \%$ after $4 \mathrm{~h}$ incubation with etoposide. After $8 \mathrm{~h}$ incubation, dead cells constituted more than $10 \%$ of the total cell number, in contrast to the control where there was no single
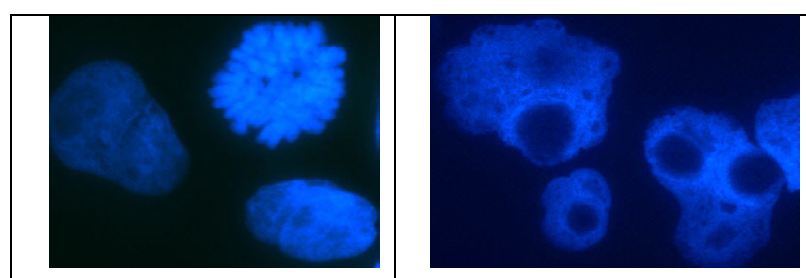

(A) 4h-control HL60

(B) 4h-etoposide HL60

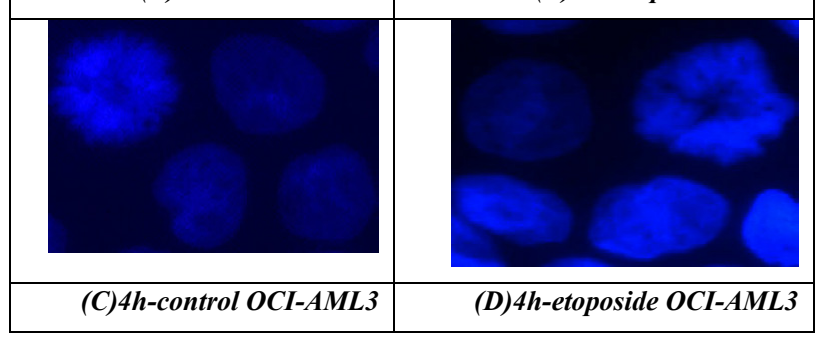

Figure 2: Images of DAPI mounted cytospins of etoHL60 and OCI-AML3, and their equivalent controls (as indicated in the figure), after 4-h incubation period.

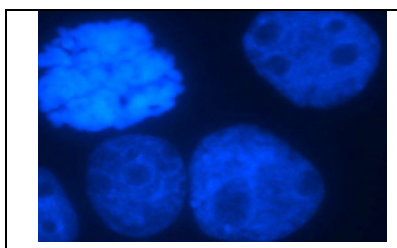

(A)24h-control HL60

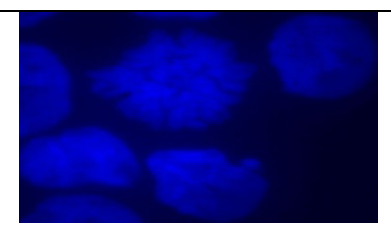

(C)24h-control OCI-AML3

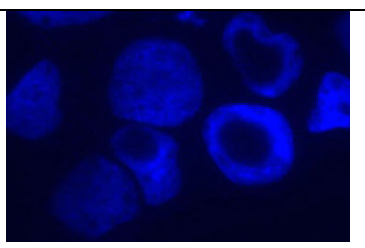

(B) 24h-etoposide HL60

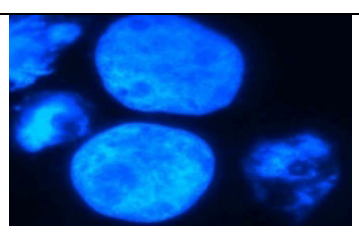

(D)24h-etoposide
$A M L 3$

Figure 3: Images of DAPI mounted cytospins of etoHL60 and OCI-AML3, and their equivalent controls, (as indicated in the figure) after $24 \mathrm{~h}$ incubation period.

dead cell after $8 \mathrm{~h}$. Further increase in the percentage of the dead cells was observed in etoHL60 culture over the $24 \mathrm{~h}$ period, and table 2 summarized cell death over this period of time. After $24 \mathrm{~h}$, the dead cells became more abundant and they constituted $34 \%$ of the total number of cells, compared to $1.5 \%$ of the untreated control. 
Citation: Khaled SAA, Burthem J, Elnoor EBEA, EIToni LF, Ahmed HN, et al. (2019) Nucleophosmin Gene Mutation in Acute Myeloblastic Leukemia: Apoptotic Role. J Blood Lymph 9: 254.

Page 4 of 7

On the other hand, the extent of the etoposide induced apoptosis of OCI-AML3 cells was insignificant as compared with the etoHL60. After $8 \mathrm{~h}$ incubation with etoposide, approx. 0.5 of etoOCI-AML3 cell culture were dead compared to $11 \%$ of etoHL60 cell culture. After 24 $\mathrm{h}$ incubation with etoposide the dead cells comprised $12.8 \%$ and $34 \%$ of the etoOCI-AML3 and etoHL60 cultures, respectively. Moreover, there was a significant delay in the response of OCI-AML3 cells to the etoposide induced apoptosis. The dead cells appeared in etoOCI-AML3 culture after $8 \mathrm{~h}$ incubation, while the appearance of the dead cells in etoHL60 culture was earlier, after only $4 \mathrm{~h}$ incubation.

In addition to the above mentioned findings, the viability study results showed that cellular death started in etoOCI-AMl3 and OCIAML3 control simultaneously. Nevertheless, the degree of death of etoOCI-AML3 cells was higher than that of the untreated control, particularly during the last $8 \mathrm{~h}$ of the $24 \mathrm{~h}$ period.

The difference in the apoptotic response between the etoposide treated HL60 and etoposide OCI-AML3, was further observed by detection of the morphological features of apoptosis in a DAPI mounted cytospins, obtained and examined as discussed before. The obtained images showed that, after 4-h incubation with etoposide most of HL60 cells exhibited the morphological characteristics of apoptosis, as compared with the control. These include irregularly shaped marginated nuclear periphery, appearance of vacuoles \& budding, and poorly defined nucleoli, as shown in Figure 1A and 1B. These changes progressed with time until most of the cells were converted to a membrane bound apoptotic bodies that contain organelles, cytosol and nuclear fragments, after $24 \mathrm{~h}$ (Figure $2 \mathrm{~A}$ and $2 \mathrm{~B}$ ).

On the contrary, these apoptotic changes were not observed in the $4 \mathrm{~h}$ etoOCI-AML3 culture, where the cells were looking like the untreated control and were continually dividing, Figure 1C and 1D. However, after 24-h incubation with etoposide, some of the OCIAML3 cells were converted into apoptotic bodies and the rest were still healthy looking cells, Figure $2 \mathrm{C}$ and 2D. The later finding denotes that apoptosis started in the etoposide treated OCI-AML3 sometime before the end of the $24 \mathrm{~h}$ period.

\section{Kinetic changes in wtNPM and mNPM during etoposide induced apoptosis of AML derived cells}

In order to study the possible pro or anti-apoptotic role of NPM whether mutated or wild, we carried out an immnuocytochemical study of NPM in cytospins from the control and etoposide treated HL60 and OCI-AML3. Cells were immunostained with antihuman NPM antibody (FC61991) that recognizes wtNPM only, and another (ab15440) that recognizes both wt \& mNPM. The antigen -antibody reactions were detected with TR and FITC conjugated species specific secondary antibodies, and the nuclei were stained with DAPI.

Images of the $4 \mathrm{~h}$ etoHL0 cytospin stained with antiNPM FC61991 showed both cytoplasmic and nucleolar staining. This was totally inconsistent with the control, where the staining was strictly nucleolar and sparing the nucleolar center. These findings denote cytoplasmic translocation of wtNPM, in most of HL60 cells after 4-h treatment with etoposide. Examination of the $24 \mathrm{~h}$ cytospins, revealed that NPM cytoplasmic translocation was irreversible and dependent on the duration and extent of the etoposide induced cytotoxicity, where the longer the duration the more the translocation and cellular damage. Moreover, cytoplasmic localization was noted to be at the expense of the nucleolar one, as shown in Figure 4.

In contrast to etoHL60 cells, the immunostaining pattern of wtNPM in 4 h etoOCI-AML3 cells was strictly nucleolar, which was similar to that of the control, besides these cells showed no signs of cytotoxicity or death. However, by the end of the $24 \mathrm{~h}$ incubation with etoposide little change in NPM staining and localization was noticed in some but not all of the etoOCI-AML3 cells. This change was manifested with cytoplasmic translocation of NPM. The translocation was concised to cells with morphological characteristics of cytotoxictiy (Figure 5).

On the other hand, immunostaining images of HL60 cytospins with antiNPM ab15440, that could recognize both wt and mNPM showed nucleolar and cytoplasmic localization in the $4 \mathrm{~h}$ and $24 \mathrm{~h}$ etocytospins. It was clear that the nucleolar localization is fainter in the $24 \mathrm{~h}$ etocytospins than the $4 \mathrm{~h}$ ones. The immunostaining pattern

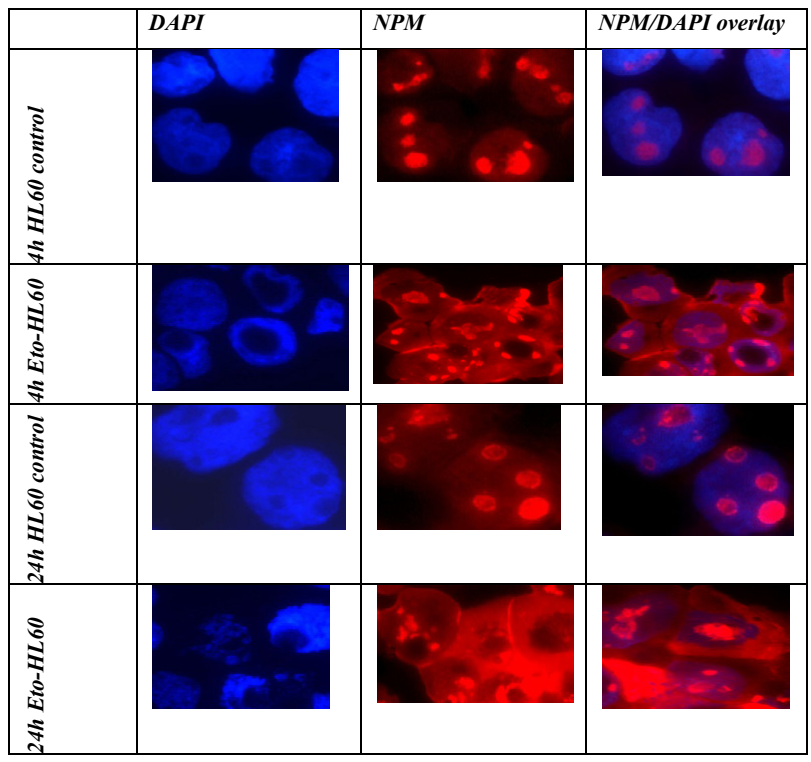

Figure 4: Immunoflourescence images of etoHL60, and their equivalen control after 4 and $24 \mathrm{~h}$ incubation period, cells were immunostained with NPM FC61991(wtNPM), with TR second layer(red) and nuclei were stained with DAPI (blue).

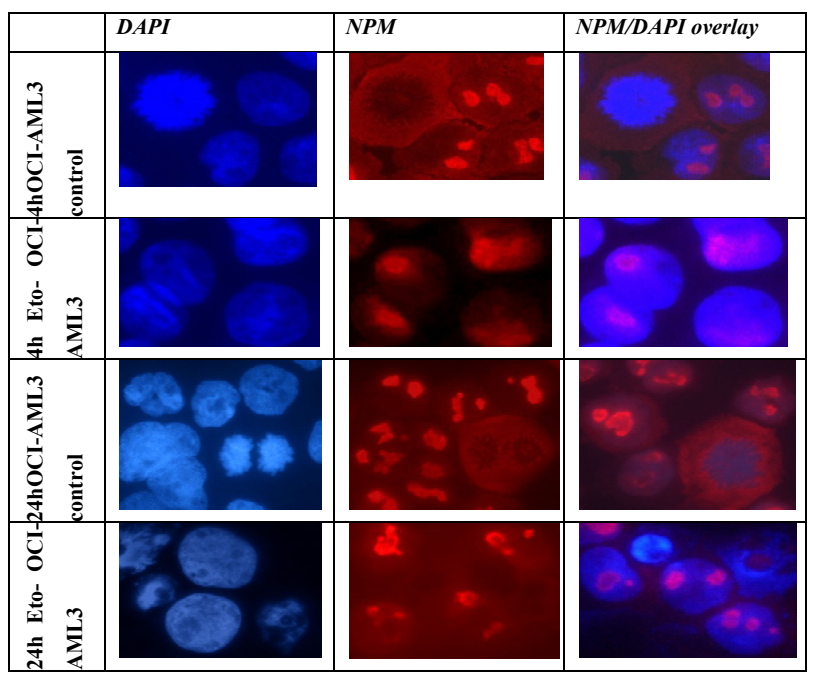

Figure 5: Immunoflourescence images of etoOCl-AML3, and their equivalent control after 4 and $24 \mathrm{~h}$ incubation period, cells were immunostained with NPM FC61991 (wtNPM), with TR second layer (red) and nuclei were stained with DAPI (blue). 
was exclusively nucleolar in the untreated cytospins, as indicated in Figure 6. These findings were similar to the staining pattern of wtNPM in HL60 cytospins. These results denote that the cytoplasmic staining represents the cytoplasmic translocation of wtNPM detected before.

Interestingly, the immunostaining pattern of the ab15440 of the OCI-AML3 control showed both nucleolar and cytoplasmic localization. The 4 and $24 \mathrm{~h}$ etoposide treated cells immunostained with the same antibody showed similar immunostaining patterns to the untreated control. However the nucleolar staining became less apparent in the $24 \mathrm{~h}$ etoposide treated cells, Figure 6.

\section{Nucleophosmin expression during etoposide induced apoptosis of AML derived cells}

To further study NPM gene mutation during etoposide induced apoptosis, we carried out a proteomic analysis of NPM protein during etoposide induced apoptosis of HL60 and OCI-AML3 cells and their untreated controls. The obtained results showed that NPM protein expression in the $24 \mathrm{~h}$ etoHL60 and etoOCI-AML3 treated lysates was approximately similar to the untreated controls. These findings were observed when blotting with NPM antibodies FC61991, ab15440 and $\mathrm{NA} 24$, as shown in Figure 7A.

On the other hand, a significant downregulation of NPM in the etoposide treated lysates, was observed when blotting with phosphor-

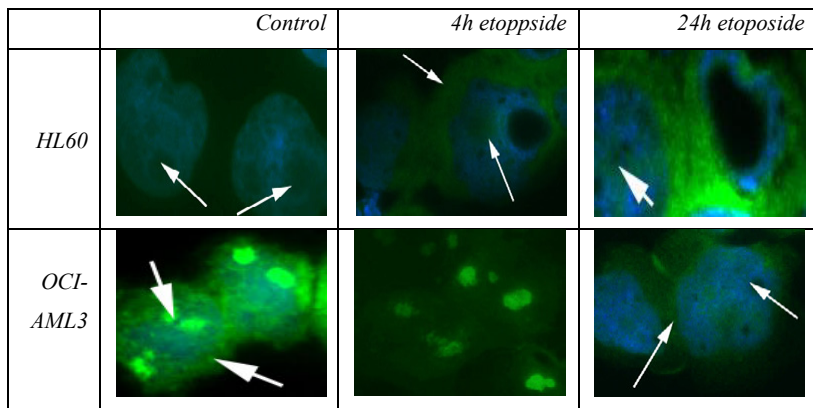

Figure 6: Immunofluorescence images of control, $4 \mathrm{~h}$ and $24 \mathrm{~h}$ Etoposide $\mathrm{HL} 60$ and OCI-AML3, as indicated in the figure, immunostained with antiNPM (ab 15440) with FITC (green) conjugated secondary antibody, nuclei were stained with DAPI (blue).

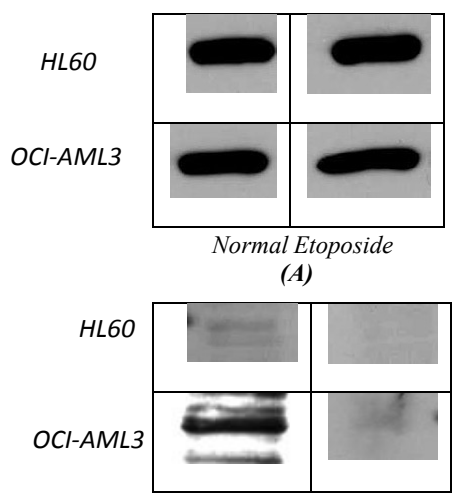

(B)

Figure 7: Immunoblotting results of normal and eto HL60 and OCI-AML3 lysates (as indicated in the figure) after $24 \mathrm{~h}$ incubation period, membranes were blotted with specific anti-NPM antibodies (A) antibody NA24, (B) antibody phospho-NPM Thr199, N.B. Blotting with antibodies FC61991 and ab15440 gave similar results to antibody NA24.
NPM Thr199. There were no protein bands detected at 37-KD (expected NPM MW), in phosphor-NPM blots of the etoposide lysates whether HL60 or OCI-AML3 lysates. These results were totally inconsistent with the results of the untreated controls. An interesting finding was that phosphor-NPM Thr199 protein expression is much higher in untreated OCI-AML3 lysates than in untreated HL60 lysates, as shown in Figure 7B.

\section{Discussion}

\section{AML cells bearing mNPM are RESISTANT TO ETOPOSIDE EFFECT}

In this study mNPM was meticulously investigated during etoposide induced apoptosis of AML cell line cells, aiming to investigate the direct or indirect effect of NPM moiety on the apoptotic response to etoposide. The study was conducted with an integration of viability studies, immunocytochemical and proteomic analyses.

The viability study results revealed that etoposide induced a potent duration dependent inhibition of HL60 cell growth. On the contrary, etoposide produced cessation of growth of OCI-AML3 cells concomitantly with the decline in the untreated control growth rate. These findings were reaffirmed by absence of mitotic figures in etoHL60 cytospins after $4 \mathrm{~h}$ only, and after $24 \mathrm{~h}$ in etoOCI-AML3 cytospins.

Taken together, these findings denote that etoposide induced growth arrest in cells expressing wtNPM, while it only potentiated the normal cellular senescence in cells bearing mNPM.

Etoposide was proposed by others as an adjunctive therapy in AML, however, the results of the clinical trials in this respect are variable and its validity is still undetermined [19]. Here, we provide evidence that the difference in the therapeutic response to etoposide, among AML patients could be related to the molecular basis of leukaemia development in each individual patient.

\section{WtNPM has a pro-apoptotic effect while mNPM has an anti- apoptotic effect}

Results of the immunocytochemical study showed cytoplasmic translocation of wtNPM during etoposide induced apoptosis of HL60 cells. This translocation was found to be related to the extent of the etoposide induced cytotoxicity. In contrast to etoHL60, this translocation was insignificant in etoOCI-AML3. These findings were consistent with the findings of Grisendi et al. [20] who found that NPM translocation occurs prior to other apoptotic events, and reported a good correlation between the degree and duration of NPM translocation and the magnitude of apoptosis. However, they did not explain the cause and effect relationship underlying these observations. Also, the findings of Colombo and his colleagues, who concluded that NPM translocation is a preliminary step in the apoptotic pathway that renders nucleolar DNA susceptible to nucleases induced damage. Thus, activates the repair mechanisms and P53, subsequently initiates apoptosis [21]. Nevertheless, their study was not conducted on cells carrying mNPM; also it was not focused on AML derived cells.

Proteomic analysis conducted after $24 \mathrm{~h}$ incubation with etoposide showed no change in NPM protein content of the etolysates; this was noted with wt, mutated and NPM fusion proteins. However, a significant downregulation was noted when blotting with phosphoNPM Thr199. These results were similar in etoHL60 and etoOCI-AML3 lysates. NPM phosphorylation at Thr199 was found to be cell cycle dependent and occurred in actively dividing cells [22]. Based on these findings together with our findings, we assumed that phospho-NPM 
Thr199 downregulation is related to the etoposide induced growth arrest rather than its cytotoxic effect. Our findings were inconsistent with the findings of Liu and Yung, who reported downregulation of NPM during sodium butyrate / vanadate induced apoptosis of HL60 cells. Furthermore, they relate the decline in NPM expression to the sodium butyrate induced apoptosis rather than the growth arrest. However, their study was based on the identification of NPM/mRNA rather than specific NPM moiety itself. Also, identification of NPM mutations was reported later [23].

Taken together, we observed that etoposide induced apoptotic cell death in cells expressing wtNPM. Cellular apoptosis was accompanied with cytoplasmic translocation of wtNPM, however the content of NPM in the same samples was unchanged. This was not the case in cells expressing $\mathrm{MNPM}$, where the extent of cell killing by etoposide was significantly reduced, besides marked delay in wtNPM translocation; also wtNPM protein levels were unchanged. On the other hand, mNPM subcellular localization and expression levels were unchanged during apoptosis. From these findings we reaffirm that wtNPM translocation is one of the biochemical events that mediates apoptosis. We also concluded that, mNPM overexpression hindered NPM translocation and accompanied with protection against apoptotic cell death by etoposide.

How mNPM expression protects cells against apoptosis, is not clear. One possible explanation is based on the results of a previous study that, derangement of nucleolar structure and contents is a very crucial step -to the apoptotic pathway and NPM is one of the most important nucleolar phosphoproteins. Nevertheless, mNPM has been found to lack the nucleolar localization motif, and is cytoplasmically localized [24]. These findings together with our findings could explain the mechanism of the anti-apoptotic effect of mNPM, that cytoplasmic translocation of the nucleolarly localized NPM (wtNPM), causes disruption of nucleolar functions and plays direct or indirect role in apoptosis. On the other hand, this will not be expected to happen with the cytoplasmically localized mNPM.

Another possible explanation is that, NPM mutation causes not only cytoplasmic localization but also deranged NPM functions. One of these functions is the regulation of P53 activities. Etoposide was found to induce apoptosis through activation of P53 and subsequently activation of the pro-apoptotic protein Bax. Thus, the anti-apoptotic effect of $\mathrm{mNPM}$, could be mediated through its direct effect on P53 [25]. However, our results contrasting the speculations by Schnittger et al. in a trial to explain the association of $\mathrm{MNPM}$ and good prognosis, they hypothesize that wtNPM protects cells from P53 induced apoptosis under stress conditions [26].

On the other hand, the anti-apoptotic effect of mNPM was supported with the results of Grisendi et al, who concluded that, the oncogenic activity of NPM seems to impinge directly and indirectly on the regulation of p53 [27]. One important mechanism involves the alternate reading frame (ARF) tumor suppressor pathway. In cells without NPM, ARF becomes unstable and delocalizes from the nucleolus, which denotes that NPM is essential for stability of ARF. This function is lost for mNPM, furthermore mNPM competes with wtNPM for ARF binding and dislocates ARF to the cytoplasm, where it is more amenable to degradation. This leads to impaired activation of P53 by ARF [28]. Thus, mNPM delays or inhibits apoptosis. In conclusion, the current study was conducted to investigate the underlying mechanism of the variable therapeutic response to etoposide treatment in de novo AML. The study speculated that molecular basis of leukemia development is the main etiology of this variability. Accordingly, viability studies, immunocytochemistry and immunoblotting experiments were done on two human leukemia cell lines, one bearing $\mathrm{mNPM}$ and the other wtNPM. The same experiments were carried out on both etoposide treated and untreated cells. The obtained results showed an antiapoptotic effect of mNPM, and suggested that mNPM protected cells from etoposide effect. However, further studies on AML samples with or without NPM mutations in the presence of etoposide are recommended.

\section{Funding}

This work was supported by the Egyptian Cultural Bureau educational grant.

\section{Disclosure}

There were no known conflicts of interest associated with this work

\section{References}

1. Dohner H, Estey EH, Amadori S, Appelbaum FR, Büchner $T$, et al. (2010) Diagnosis and management of acute myeloid leukemia in adults: recommendations from an international expert panel, on behalf of the European Leukemia Net. Blood 115: 453-74.

2. Juliusson G, Antunovic P, Derolf A, Lehmann S, Möllgård L, et al. (2009) Age and acute myeloid leukemia: real world data on decision to treat and outcomes from the Swedish Acute Leukemia Registry. Blood 113: 4179-87.

3. Schlenk RF, Dohner K, Kneba M, Götze K, Hartmann F, et al. (2009) Gene mutations and response to treatment with all-trans retinoic acid in elderly patients with acute myeloid leukemia. Results from the AMLSG Trial AML HD98B. Haematologica 94: 54-60.

4. Mro'zek K, Marcucci G, Nicolet D, Maharry KS, Becker H, et al. (2012) Prognostic significance of the European LeukemiaNet standardized system fo reporting cytogenetic and molecular alterations in adults with acute myeloid leukemia. J Clin Oncol 30: 4515-23.

5. Falini B, Mecucci C, Tiacci E, Alcalay M, Rosati R, et al. (2005) Cytoplasmic nucleophosmin in acute myelogenous leukemia with a normal karyotype. $\mathrm{N}$ Engl J Med 352: 254-66.

6. Falini B, Nicoletti I, Martelli MF, Mecucci C (2007) Acute myeloid leukemia carrying cytoplasmic/mutated nucleophosmin (NPMC+ AML): biologic and clinical features. Blood 109: 874-85

7. Falini B, Sportoletti P, Martelli MP (2009) Acute myeloid leukemia with mutated NPM1: Diagnosis, prognosis and therapeutic perspectives. Curr Opin Oncol 21: 573-81.

8. Falini B, Tiacci E, Martelli MP, Ascni S, Pileri SA (2010) New classification of acute myeloid leukemia and precursor-related neoplasms: changes and unsolved issues. Discov Med 53: 281-92.

9. Bertwistle D, Sugimoto M, Sherr CJ (2004) Physical and functional interactions of the Arf tumor suppressor protein with nucleophosmin/B23. Mol Cell Biol 24 985-96.

10. Slevin ML, Joel SP (1993) Prolonged oral etoposide in small cell lung cancer An Oncol 4: 529-32.

11. Archimbaud E, Leblond V, Michallet M, Cordonnier C, Fenaux P, et al. (1991) Intensive sequential chemotherapy with mitoxantrone and continuous infusion etoposide and cytarabine for previously treated acute myelogenous leukemia. Blood 77: 1894-1900.

12. Amadori S, Arcese W, Isacchi G, Meloni G, Petti MC, et al. (1991) Mitoxantrone etoposide, and intermediate-dose cytarabine: An effective and tolerable regimen for the treatment of refractory acute myeloid leukemia. J Clin Oncol 9: 1210-14.

13. Kantarjian HM, Erba HP, Claxton D, Arellano M, Lyons RM, et al. (2010) Phase II study of clofarabine monotherapy in previously untreated older adults with 
Citation: Khaled SAA, Burthem J, Elnoor EBEA, EIToni LF, Ahmed HM, et al. (2019) Nucleophosmin Gene Mutation in Acute Myeloblastic Leukemia: Apoptotic Role. J Blood Lymph 9: 254.

acute myeloid leukemia and unfavorable prognostic factors. J Clin Oncol 28: 549-55.

14. Khaled SA, Burthem J, Abo EINoor E, El Toni L, Ahmed S, et al. (2018) The mutated cytoplasmic form of nucleophosmin expressed by the cell line $\mathrm{OCl}$ AML3 is phosphorylated on Thr199: implications for the pathogenesis of primary acute myeloid leukaemia (AML).

15. Khaled SA, Burthem J, Abo EINoor E, El Toni L, Ahmed S, et al. (2015) Differences between nucleophosmin isoforms in de-novo acute myeloid leukemia: possible implications in developing targeted therapy for acute myeloid leukemia with normal karyotype. Egyptian J Hematol 40: 190-4.

16. Khaled SA, Burthem J, EINoor E, Toni L, Ahmed S, et al. (2018) Role of nucleophosmin gene mutation in leukemogenesis of acute myeloid leukemia. J Hematol 7: 7-13.

17. Quentmeier H, Martelli MP, Dirks WG, Bolli N, Liso A, et al. (2005) Cell line OCI/AML3 bears exon-12 NPM gene mutation-A and cytoplasmic expression of nucleophosmin. Leukaemia 19:1760-7.

18. Towbin H, Staehelin T, Gordon J (1979) Electrophoretic transfer of proteins from polyacrylamide gel to nitrocellulose sheets: procedure and some applications. Pro Natl Acad Sci USA, 76: 4350-54.

19. Tallman S, Gilliland D, Rowe M (2005) Drug therapy for acute myeloid leukemia Blood 4: 1154-63.

20. Grisendi S, Mecucci C, Falini B, Pandolfi PP (2006) Nucleophosmin and cancer. Nat Rev Cancer 6: 493-505.
21. Colombo E, Marine JC, Danovi D, Falini B, Pelicci PG (2002) Nucleophosmin regulates the stability and transcriptional activity of p53. Nat Cell Biol 4: 529-33.

22. Tokuyama Y, Horn HF, Kawamura K, Tarapore P, Fukasawa K (2001) Specific phosphorylation of nucleophosmin on $\mathrm{Thr}(199)$ by cyclin-dependent kinase 2-cyclin $\mathrm{E}$ and its role in centrosome duplication. J Biol Chem 276: 21529-53.

23. Liu WH, Yung BY (1998) Mortalization of human promyelocytic leukemia HL60 cells to be more susceptible to sodium butyrate-induced apoptosis and inhibition of telomerase activity by down-regulation of nucleophosmin/B23. Oncogene 17: 3055-64.

24. Mariano AR, Colombo E, Luzi L, Martinelli P, Volorio S, et al. (2006) Cytoplasmic localization of NPM in myeloid leukemias is dictated by gain-offunction mutations that create a functional nuclear export signal. Oncogene 25: 4376-80.

25. Li J, Zhang X, Sejas DP, Pang Q (2005) Negative regulation of p53 by nucleophosmin antagonizes stress-induced apoptosis in human normal and malignant hematopoietic cells. Leuk Res 29: 1415-23.

26. Schnittger S, Schoch C, Kern W, Mecucci C, Tschulik C, et al. (2005) Nucleophosmin gene mutations are predictors of favourable prognosis in acute myelogenous leukemia with a normal kayotype. Blood 106: 3733-39.

27. Grisendi S, Mecucci C, Falini B, Pandolfi PP (2006) Nucleophosmin and cancer. Nat. Rev. Cancer 6: 493-505.

28. Colombo E, Martinelli P, Zamponi R, Shing DC, Bonetti P, et al. (2006) Delocalization and destabilization of the Arf tumor suppressor by the leukemiaassociated NPM mutant. Cancer Res 66: 3044-50. 